\title{
Tribological behavior of co-textured cylinder liner-piston ring during running-in
}

\author{
Chenwei MIAO ${ }^{1,2}$, Zhiwei GUO ${ }^{1,2, *}$, Chengqing YUAN ${ }^{1,2}$ \\ ${ }^{1}$ School of Energy and Power Engineering, Wuhan University of Technology, Wuhan 430063, China \\ ${ }^{2}$ Reliability Engineering Institute, National Engineering Research Center for Water Transportation Safety, Wuhan 430063, China \\ Received: 08 October 2019 / Revised: 17 March 2020 / Accepted: 29 January 2021 \\ (C) The author(s) 2021.
}

\begin{abstract}
The running-in of cylinder liner-piston rings (CLPRs) is the most important process that must be performed before a marine diesel engine can be operated. The quality of running-in directly affects the reliability of a CLPR. The surface texture of a CLPR has been proven to significantly affect its lubrication performance. In this study, the tribological behavior of a CLPR during running-in is investigated. Three types of surface textures are generated on the CLPR via laser processing: dimple texture on piston rings, groove texture on cylinder liners, and co-texture on both sides. Subsequently, a series of tests are performed on a slice tester. A load of $300 \mathrm{~N}$ (1.64 MPa) is applied, and two speeds (50 and $100 \mathrm{rpm}$ ) are adopted. The CLPR running-in quality is characterized based on three parameters, i.e., the friction coefficient, contact resistance, and wear topography. Experimental results show that, compared with a non-textured surface, the three types of surface textures mentioned above improved the friction performance during running-in. The lubricant supply capacity of the dimple texture on the piston ring, as a mobile oil reservoir, is stronger than that of the groove texture on the cylinder liner serving as a static oil reservoir. By contrast, the wear resistance of the dimple texture, as a movable debris trap on the piston ring, is weaker than that of the groove texture on the cylinder liner, which serves as a static debris trap. It is demonstrated that the co-texture combines the advantages of dimples and groove textures. Compared with non-textured surfaces, the friction coefficient decreased the most at $100 \mathrm{rpm}$ $(44.5 \%)$, and the contact resistance improved the most at $50 \mathrm{rpm}(352.9 \%)$. The coupling effect provides the surface with improved running-in quality by optimizing the tribological performance, particularly at the dead center. This study provides guidance for the tribological design and manufacturing of CLPR in marine diesel engines.
\end{abstract}

Keywords: marine diesel engine; cylinder liner-piston ring; running-in process; co-texture; tribological performance

\section{Introduction}

The cylinder liner-piston ring (CLPR) wear process comprises different stages, in which running-in is inevitable prior to steady wear [1]. In particular, running-in is an important process for new or overhauled CLPRs before they are used. When runningin commences, the CLPR undergoes a transient period, which results in an increase in the actual contact area. This increase is due to the gradual wear and tear of two complexes, particularly the flattening of sharp and rough surfaces [2,3]. Running-in transforms the lubrication mode from boundary and mixed lubrication to hydrodynamic lubrication. It can prevent gluing, reduce the wear rate, improve the reliability, and extend the service life $[4,5]$. The running-in quality not only directly affects the lubrication performance of the steady wear process, but also affects fuel consumption and air tightness [6]. Hence, the lubrication performance of the CLPR during

* Corresponding author: Zhiwei GUO, E-mail: zwguo@whut.edu.cn 
running-in must be improved. Operating conditions, surface topography, operating media, and running-in duration are factors that affect the quality of runningin $[7,8]$. The operating conditions and operating media of a marine diesel engine are determinants. Hence, surface topography is a key factor affecting running-in quality.

Surface texturing is a new surface treatment technology originating from bionics. It can yield desirable surface properties by machining a certain topography on friction pair surfaces under oil lubrication. The lubricating oil stored in the texture can provide a certain pressure, which depends on the operating conditions, texture parameters, types, and supply of lubricating oil [9-12]. Moreover, textures can store wear debris and prevent it from repeatedly scratching the surface $[13,14]$. Surface texturing is effective in improving the lubrication characteristics of CLPRs [15-17]. Morris et al. [18] and Yin et al. [19] independently established numerical models to prove that the dimple texture on a cylinder liner is beneficial to the friction performance of CLPRs. Guo et al. [20] and Shen et al. [21] experimentally validated this hypothesis. It is noteworthy that grooves are a type of texture that is typically used in cylinder liners. Based on simulation results, Mohamad et al. [22] discovered that cylinder liner oil grooves can be used efficiently to maintain the hydrodynamic effect, and optimum surface texturing might substantially reduce friction losses. Rao et al. [23] optimized the width of thread grooves to achieve better friction performance through a cylinder liner test. Owing to the limitation of machinable areas, the option of texture on the piston ring was fewer compared to that on the cylinder liner. Consequently, dimples are the most feasible textures on piston rings [24]. Kligerman et al. [25] developed an analytical model to evaluate the optimum dimple parameters such as dimple depth, texture area density, and textured portion of the nominal contact surface of a piston ring. Shen and Khonsari [26] and Zhang et al. [27] conducted the experiments and discovered that (i) the friction performance of the ring surface improved significantly via surface texturing, (ii) the running-in duration shortened, and (iii) the sealing performance improved.

To improve the efficiency and reliability of diesel engines, surface texture is a potential technology, which can be adapted for low-speed and heavy-load marine diesel engines. The cylinder liner or piston ring is typically regarded as a separate component when a surface texture is applied. However, as an integral part of the friction pair, the texture of the cylinder liner or piston ring should be considered simultaneously. Research regarding co-textured CLPRs, particularly the running-in process, is insufficient. This study was conducted to provide a reference for the texture design of CLPRs in marine diesel engines. First, texture patterns were generated on the surfaces of the cylinder liners and piston rings via laser processing. Subsequently, a series of experiments were conducted on a reciprocating slicing tester to evaluate the lubrication performance of textured CLPRs during running-in and to investigate its mechanism. The amount of friction reduction, oil film characteristics, and morphological features of the co-textured surface were analyzed and compared with those of non-textured and singletextured surfaces.

\section{Experimental}

\subsection{Experimental device}

All the experiments were conducted using a reciprocating sliding tester. A schematic diagram of the sliding tester and the dimensions of the CLPR slices are shown in Fig. 1. The tester can simulate a

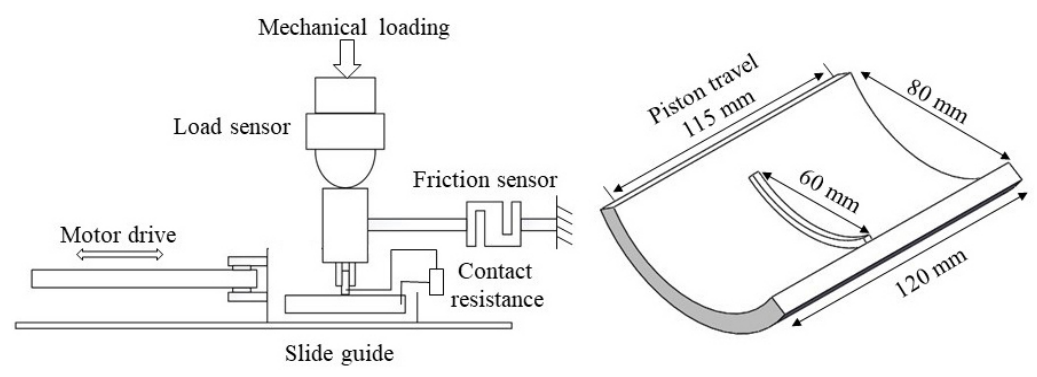

Fig. 1 Schematic diagram of slicing tester and dimensions of CLPR slices. 
marine diesel engine under various operating conditions: rotational speed, applied load, and lubrication oil supply. However, the tester differs from the actual diesel engine. Periodic high temperature and pressure due to combustion, which is not conducive to lubrication, cannot be simulated. The cylinder liner slices measured $120 \mathrm{~mm} \times 80 \mathrm{~mm}$. The chord of the piston ring slices was $60 \mathrm{~mm}$ long. The reciprocating action was provided by the motor and crank train. The piston ring travel distance was $115 \mathrm{~mm}$. A load sensor was used to ensure load stability. The friction resistance was measured using a horizontal friction sensor. An oil film measuring system based on the contact resistance principle was assembled in the tester. Two wires were tied to the cylinder liner and piston ring slices, separately.

\subsection{Test sample preparation}

The test samples were cut from intact CLPRs of the S195 small marine diesel engine. The cross-sectional shape of the piston ring was rectangular. The material of the cylinder liner was a wear-resistant boron cast iron. The piston ring slices were made of untreated ductile iron gas rings. To achieve a fully contacting and interacting co-texture, a dimple texture on the piston ring and a groove texture on the cylinder liner were implemented.

Laser surface texture has been proven to be a convenient and effective processing method for CLPRs [28]. Groove and dimple textures were independently machined on cylinder liners and piston rings via laser processing. The texture parameters were based on existing studies and have been proven effective [23, 29]. The processed samples of the CLPR are shown in Fig. 2, and the texture parameters are listed in Table 1. The cylinder liner comprised 10 parallel rectangular groove textures. The groove texture was $40 \mathrm{~mm}$ in length, $1 \mathrm{~mm}$ in width, and $120 \pm 10 \mu \mathrm{m}$ in depth. The interval between two adjacent grooves was $10 \mathrm{~mm}$, and the angle between the groove texture and cylinder liner was $30^{\circ}$. The coverage was $5.0 \%$. When the piston ring was compressed, two circular dimple textures were machined at $4^{\circ}$ of rotation angle.. The diameter and depth of the dimple texture were $1 \mathrm{~mm}$ and $120 \pm$ $10 \mu \mathrm{m}$, respectively. The interval between the centers of two adjacent grooves was $1.2 \mathrm{~mm}$. The coverage rate was $14.5 \%$.

\subsection{Wear experiments}

The experiments were performed to investigate the lubrication performance of the co-textured CLPR during running-in and compare it with non-textured and single-textured CLPRs. The experimental groups are listed in Table 2.

Each group of the experiment lasted for $4 \mathrm{~h}$, whereas the normal running-in process lasted for 1-2 $\mathrm{h}$. The running-in load was $300 \mathrm{~N}$, and the pressure calculated by dividing the load by the contact area was approximately 1.64 MPa. Two running-in speeds were used: $50 \mathrm{rpm}$ (I) and $100 \mathrm{rpm}$ (II), both of which were simulated using a low-speed marine diesel engine. To observe the lubricating behavior more clearly, a $70 \mathrm{~N}$ base oil without additives was used as the lubricant. The CLPR may be in starved or fully
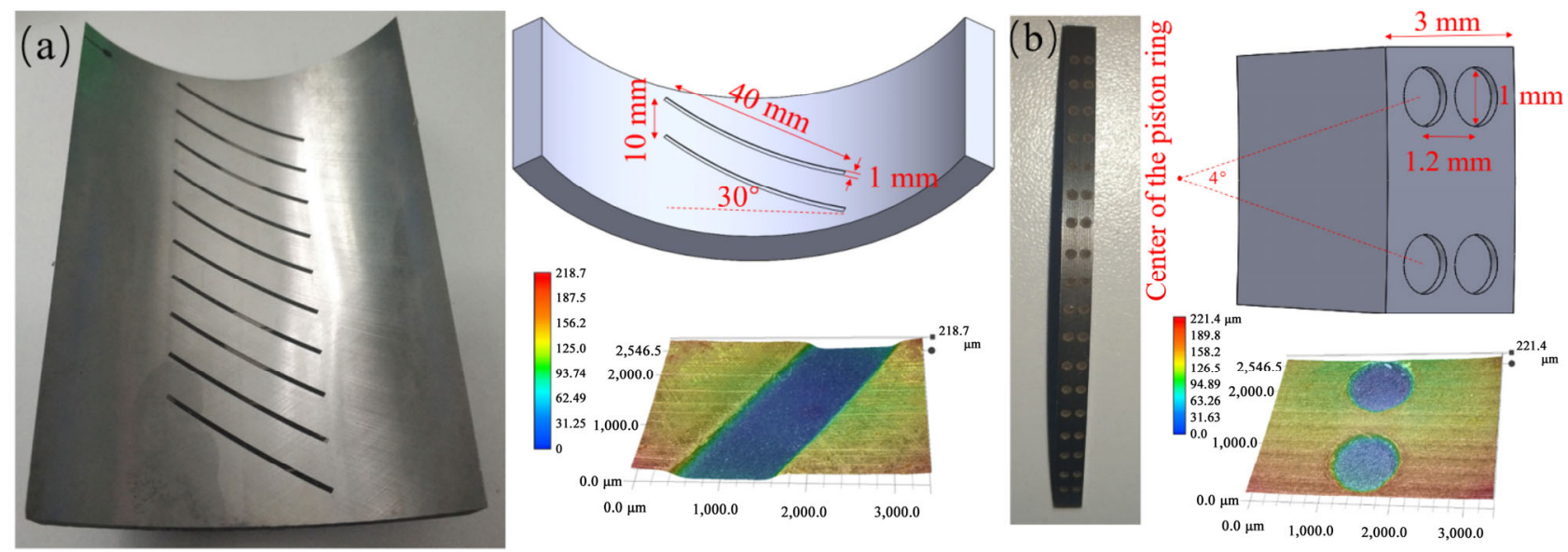

Fig. 2 Processed samples of the cylinder liner-piston ring: (a) cylinder liner and (b) piston ring. 
Table 1 Structural texture parameters.

\begin{tabular}{ccc}
\hline Parameter & Groove & Dimple \\
\hline Shape & Rectangle & Circular \\
Length $(\mathrm{mm})$ & 40 & 1 \\
Width $(\mathrm{mm})$ & 1 & - \\
Depth $(\mu \mathrm{m})$ & $120 \pm 10$ & $120 \pm 10$ \\
Interval $(\mathrm{mm})$ & 10 & 1.2 \\
Angle $\left({ }^{\circ}\right)$ & 30 & 4 \\
Coverage $(\%)$ & 5.0 & 14.5 \\
\hline
\end{tabular}

Table 2 Experiment settings.

\begin{tabular}{ccc}
\hline Group & Cylinder liner & Piston ring \\
\hline A & Non-textured & Non-textured \\
B & Textured & Non-textured \\
C & Non-textured & Textured \\
D & Textured & Textured \\
\hline
\end{tabular}

flooded lubrication, depending on its operating conditions. The lubricating oil was injected into CLPRs at a rate of $1 \mathrm{~mL} / \mathrm{min}$, which was significantly greater than the actual consumption. The contact was fully flooded by supplying oil such that the experimental variables were not affected by the amount of lubricant. The viscosity of the $70 \mathrm{~N}$ base oil was $13 \mathrm{~mm}^{2} / \mathrm{s}$ at $40{ }^{\circ} \mathrm{C}$. The experiments were performed at room temperature, which ranged from 20 to $40{ }^{\circ} \mathrm{C}$. Because the properties of the $70 \mathrm{~N}$ base oil were stable, the effects of temperature variation were negligible.

\subsection{Characterization of running-in quality}

Figure 3 shows the system to evaluate the running-in quality. The running-in quality of the non-textured and textured CLPRs was evaluated based on the energy loss, running-in efficiency, lubrication performance, and surface characteristics. Three parameters, $S_{\mathrm{q}}, S_{\mathrm{bi}}$,

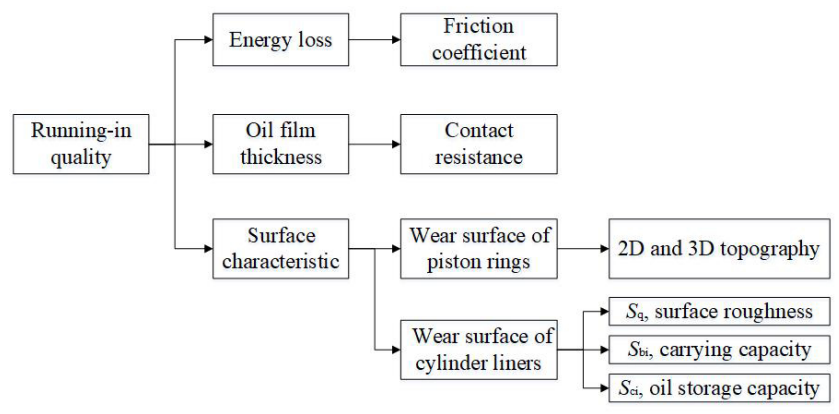

Fig. 3 System for evaluating running-in quality. and $S_{\mathrm{ci}}$ [30], were used in the evaluation system. $S_{\mathrm{q}}$ represents the smoothness of the surface. $S_{b i}$ is the surface bearing index, which is the ratio of $S_{\mathrm{q}}$ to the contour height at $5 \%$ contour bearing area; it denotes the load-carrying capacity of the surface. $S_{\mathrm{ci}}$ is the core fluid retention index, which is the ratio of the body volume to $S_{\mathrm{q}}$ per unit area in the central region. The evaluation criteria used are specific introduced next.

Energy loss is an important index for describing the operating efficiency of CLPRs. The friction coefficient is the ratio of friction to the applied force. It can intuitively reflect the frictional resistance between friction pairs; hence, the energy loss caused by friction can be determined. The friction coefficient was measured throughout the experiment, and the sampling frequency was $1,000 \mathrm{~Hz}$. The average friction coefficient over time and the instantaneous friction coefficient of one stroke at $0,0.5,1,2$, and $4 \mathrm{~h}$ were used in the analysis. The average friction coefficient is the average value of the instantaneous friction coefficient of a reciprocating motion.

The contact resistance can qualitatively and directly represent the CLPR oil film thickness based on the resistance between the CLPRs [31]. The contact resistance was calculated from the measured voltage. The acquisition and use of the contact resistance were consistent with the friction coefficient.

Surface characteristics are an important criterion for evaluating the running-in quality. The wear morphology after running-in affects the wear rate, oil film-forming capacity, and load-bearing capacity during running-in. The wear topography comprises two parts: the wear surface of the piston rings and the wear surface of the cylinder liners. The wear topography was measured after the completion of the experimental cycle. Although the final period of the experiments had entered a stable wear process, the effect of the stable wear process on the surface morphology was less prominent than that of running-in. The wear topography of the piston rings was obtained using a super-depthof-field microscope (VHX-2000, KEYENCE, Japan) to observe the surface wear. The observation magnification was 1000X. The worn surface of the cylinder liner was measured using a laser interferometer profilometer (LI-3, Huazhong University of Science and Technology, China). The surface roughness parameters of the cylinder liner were used to evaluate the surface 
characteristics. The dimensions of the measuring area were $0.8 \mathrm{~mm} \times 0.8 \mathrm{~mm}$. This represents the oil-storage capacity of the surface core area. The smaller value of $S_{q}$ and larger values of $S_{b i}$ and $S_{c i}$ indicate that the running-in quality of the worn surface is higher. The surface topography of the cylinder liner before wear is presented in Fig. 4 . The values of $S_{\mathrm{q}}, S_{\mathrm{bi}}$, and $S_{\mathrm{ci}}$ are $0.430,0.586$, and 2.227 , respectively.

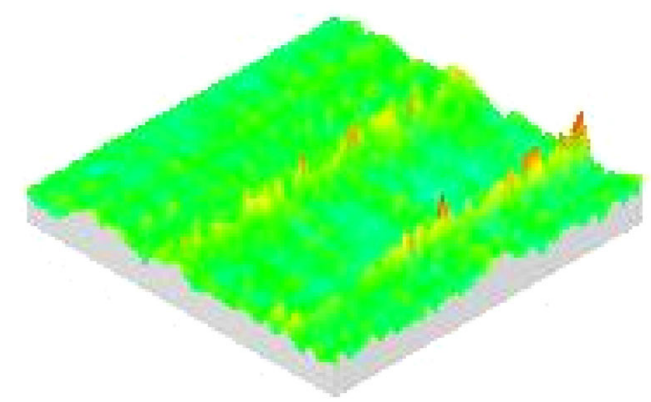

Fig. 4 Surface topography of cylinder liner before wear.

\section{Results and discussion}

\subsection{Friction coefficient}

Figure 5 shows the average friction coefficient of the experimental groups with respect to the running-in duration. With reference to the running-in duration, the average friction coefficients of groups A, B, C, and $\mathrm{D}$ decreased with time. Among them, the extent of decrease in D-II was the largest (38.4\%), whereas that of B-I was the smallest (21.4\%). Running-in reduced the damage to the oil film by flattening the peaks on the contact surfaces. When the peaks on both sides of the contact surface were smoothed and the oil film was stabilized, stable wear occurred. The variation in the friction coefficient reduced significantly. It was observed that group A had a greater average friction coefficient than the textured CLPR under all operating conditions and durations of the experiments; this indicated that the texture of this structural parameter had anti-friction properties. The oil storage capacity of the texture can reduce the friction coefficient to a certain extent. Meanwhile, group D had the lowest friction coefficient, thereby proving the feasibility of the co-texture. The co-texture exhibited the best frictionreduction performance and the lowest friction energy loss. After the stable wear process occurred, the friction coefficient of group A was used as a reference. At $50 \mathrm{rpm}$, the average friction coefficients of groups B, C, and D decreased by $15.8 \%, 24.7 \%$, and $34.2 \%$, respectively. At a speed of $100 \mathrm{rpm}$, the average friction coefficients of groups B, C, and D decreased by $17.4 \%$, $28.5 \%$, and $44.5 \%$, respectively. A comparison of the friction coefficients of groups $B$ and $C$ shows that the friction reduction performance of group $C$ was better than that of group B. As small oil reservoirs, the texture of the piston ring can supplement the oil film with the movement of the piston ring. By contrast, the texture on the cylinder liner was effective only when the piston ring was swept through the texture region. This resulted in the formation and replenishment of an oil film in group B, which was inferior to that of group $\mathrm{C}$, and the friction coefficient was correspondingly greater. From low to high, the energy saving level was ranked as groups A, B, C, and D.

When focusing on one stroke in these periods, it was observed that the instantaneous friction coefficients differed significantly, as shown in Fig. 6. The first stroke was selected at the start of the measurements. Time $t_{1}$ and $t_{2}$ referred to the time of one stroke, which were 0.6 and $0.3 \mathrm{~s}$, respectively. Whether based on the running-in duration or texture type, the overall characteristics of the instantaneous friction coefficient
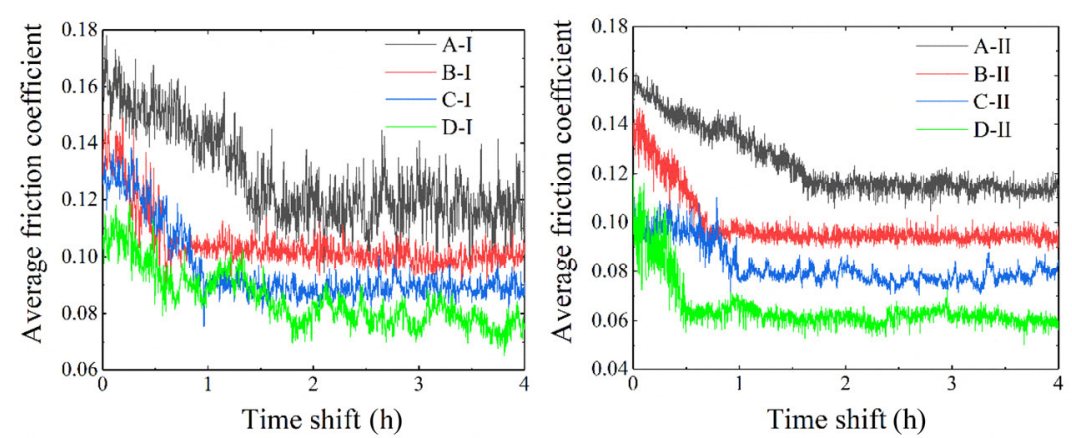

Fig. 5 Average friction coefficient of experimental groups (groups A-D, Table 2) with respect to time: I-50 rpm and II-100 rpm. 

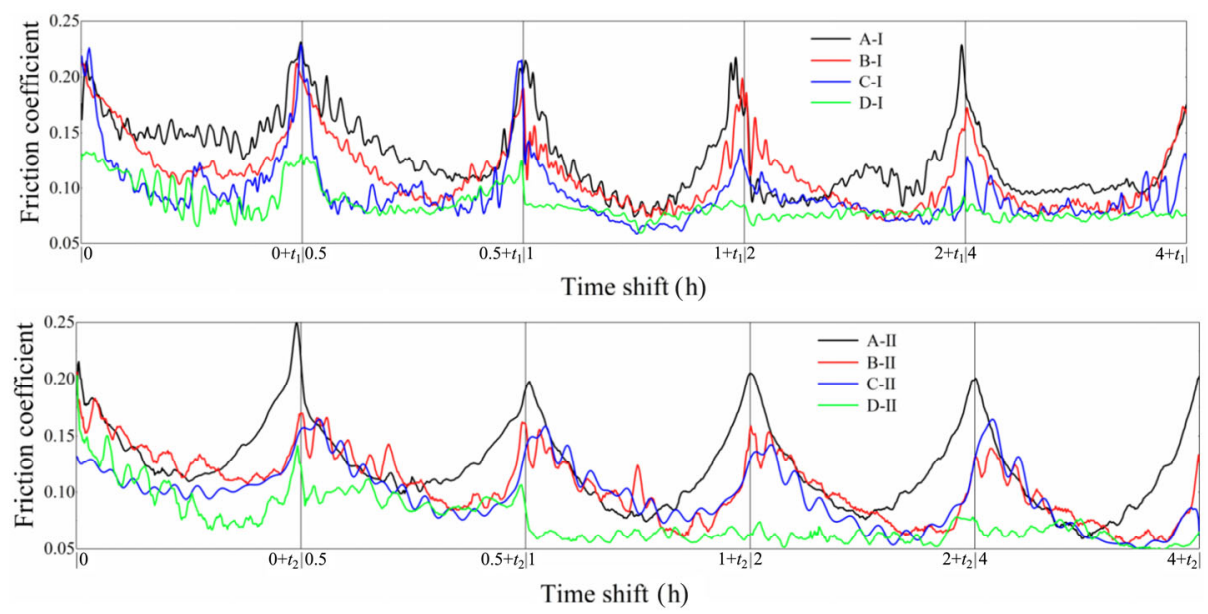

Fig. 6 Time-dependent variation of instantaneous friction coefficient of a stroke (groups A-D, Table 2): I-50 rpm and II-100 rpm.

were similar to those of the average friction coefficient. The difference analysis primarily focused on comparative interpretation within one stroke. Except for group D, all friction coefficients in the other stroke groups exhibited a U-shaped profile. The friction coefficient of the dead center was greater than that of the middle. Because of the steady speed and small acceleration in the middle, the oil film formed stably, and the friction coefficient was low. The oil film could not be stabilized, and the friction coefficient was high at the dead center because the speed was approximately zero and the acceleration was high.

Under conditions I and II, the non-textured CLPR group A exhibited the same variation. As time progressed, the friction coefficient of the dead center remained unchanged, whereas the friction coefficient in the middle of the stroke decreased significantly. The poor lubrication condition of the dead center resulted in mixed lubrication or dry friction in the CLPR. The wear debris was scraped repeatedly at the dead center, thereby resulting in a scratched surface. The friction coefficients of groups B, C, and D differed from that of group A, and they not only decreased in the middle, but also decreased to a certain extent at the dead center as running-in progressed. The oil storage capacity of the texture provided lubrication, and the wear debris trapping capacity optimized the running-in conditions. Therefore, even when the speed of the stop point was approximately zero, running-in gradually changed the dead center from dry friction to mixed lubrication. This indicates that the capacity of oil storage and debris trapping can improve the lubrication performance at the dead center when the friction pair is sliding at a low speed.

During the entire wear process, the co-textured CLPR exhibited different characteristics. The difference in friction coefficient between the dead center and the middle was much smaller than that of the other three groups in the first half hour. However, the friction coefficient no longer exhibited the U-shaped behavior and became smooth after stable wear occurred. When the piston ring passed through the groove texture, the lubricant in the groove texture can be supplemented to the dimple texture owing to extrusion. The coupling effect of the co-texture yielded the greatest friction coefficient reduction at the dead center.

The friction coefficient is an important parameter for evaluating friction performance in both modeling and testing. A comparison between the friction coefficient calculated by modeling and that obtained by testing can verify the accuracy of the model. The obtained results imply that the model can be optimized and improved to yield a more realistic performance prediction.

\subsection{Contact resistance}

Figure 7 shows the average contact resistance of the experimental groups with respect to time. Compared with the average contact resistance under the two conditions, the oil film thickness at a higher speed was larger than that at a lower speed. When the piston ring moved, oil pressure was established on the contact surface to form an oil film. Because of the viscous nature of the lubricant, the lubricating film gradually 

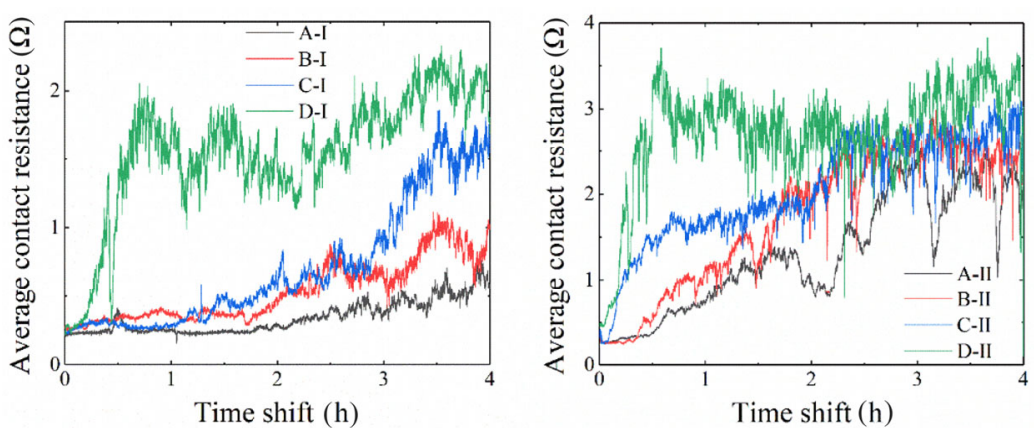

Fig. 7 Average contact resistance of experimental groups (groups A-D, Table 2) with respect to time: I-50 rpm and II-100 rpm.

disappeared after the piston ring was removed. The increase in the piston ring speed shortened the interval of the oil film re-formation, thereby improving the oil-film-forming ability. In addition, the oil film thickness of the four textures corresponded to the average friction coefficient. Compared with the average contact resistance $(0.34 \Omega)$ of the non-textured surface at $50 \mathrm{rpm}$, the average contact resistances of groups B, C, and D increased by $58.8 \%, 108.8 \%$, and $352.9 \%$, respectively. Compared with the average contact resistance $(1.31 \Omega)$ of the non-textured surface at $100 \mathrm{rpm}$, the average contact resistances of groups B, C, and D increased by $33.6 \%, 57.3 \%$, and $92.4 \%$, respectively. The larger the oil film thickness, the smaller was the friction coefficient. It was demonstrated that oil film thickness was one of the key factors affecting the friction coefficient. The co-texture had the largest oil film thickness, which formed earlier in the initial stage of the test. This occurred primarily because the lubricants stored in the texture complemented each other.

Figure 8 shows the instantaneous contact resistance in one stroke for different experimental groups. The first stroke in the measurement period was selected. The crank angle is the angle that the crank rotates from one dead center to the other, and the angle of one stroke is $180^{\circ}$. The contact resistance of all experimental groups increased with the running-in time. Subsequently, it stabilized during the stable wear stage. The contact resistance and friction coefficient showed this characteristic simultaneously. Running-in increased the actual contact area between the friction pairs by flattening the peaks of the contact surface, thereby facilitating the formation and stability of the oil film. Furthermore, by guaranteeing a certain speed and pressure, the friction pair was under hydrodynamic lubrication. As shown in Fig. 8 A-I, the contact resistance of the middle increased continuously during running-in, whereas the contact resistance of the dead center was always approximately zero and no significant changes were observed. This shows that speed was an important
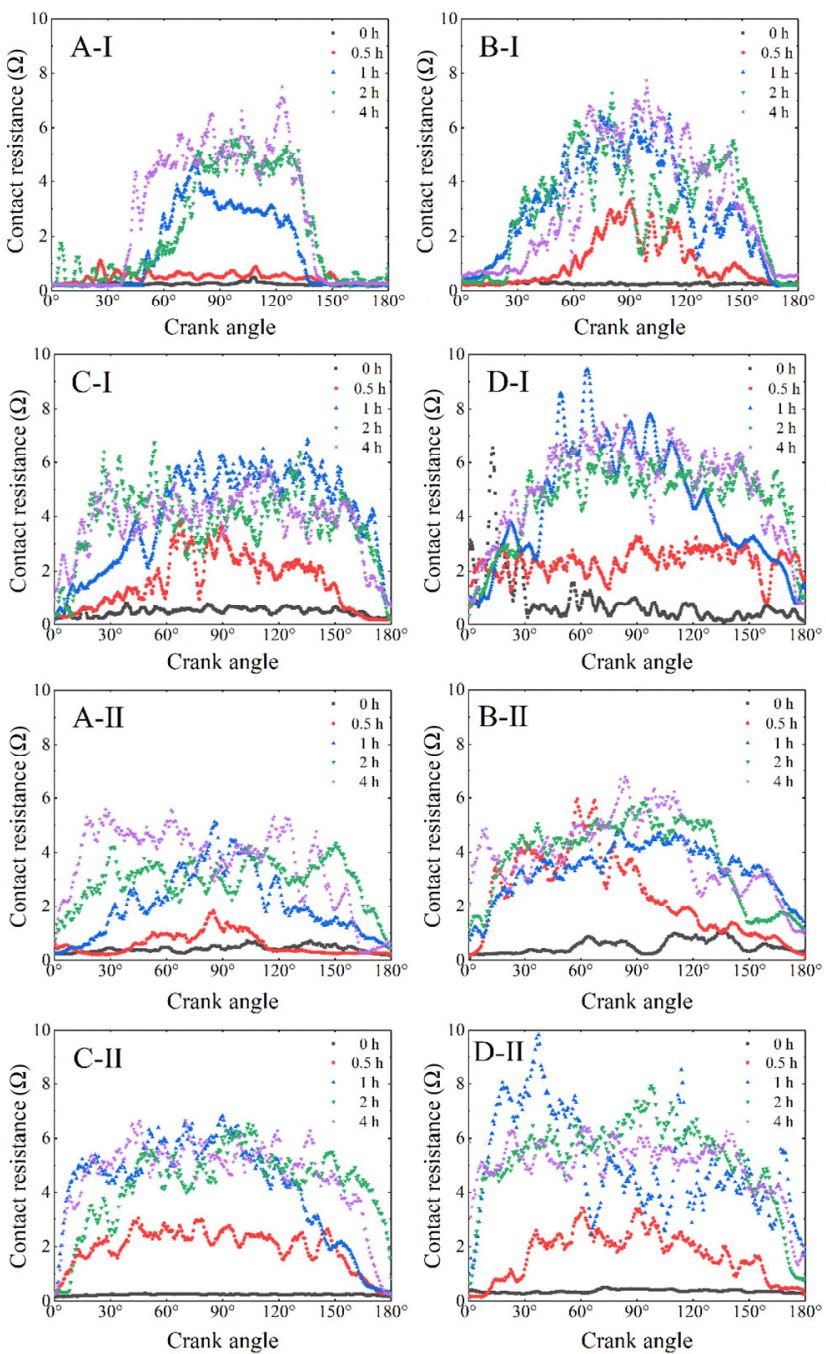

Fig. 8 Contact resistance in one stroke for different experimental groups (groups A-D, Table 2): I-50 rpm and II-100 rpm. 
factor in determining the formation of the oil film. Moreover, the irremovable debris accumulated in the dead center, scratched the surface repeatedly, and generated new debris.

In terms of the texture types, the results from experimental groups A, B, C, and D indicated significant differences. Comparing Figs. 8 A-I and B-I, the crank angle with contact resistance increased from $120^{\circ}$ $\left(30^{\circ}-150^{\circ}\right)$ to $150^{\circ}\left(15^{\circ}-165^{\circ}\right)$. As a static oil reservoir, the groove texture was not effective at all time. When the piston ring passed through the grooves, the lubricating oil was ejected from the grooves into the contact through the "inlet suction" mechanism. $[15,32]$. The groove texture provided lubricating oil to form an oil film. The dimple texture in group $\mathrm{C}$ served as a movable oil reservoir, providing lubricating oil to the piston ring at all time. Therefore, its contact resistance was higher than those of groups A and B in the entire stroke, particularly in the dead center. Hence, the friction coefficient of group $C$ was lower than those of groups A and B. The contact resistance of group D was the highest among all the experimental groups, indicating that group D possessed the best oil film characteristics.

Regarding the running-in speed, the oil film characteristics of condition II were better than those of condition I. The increase in speed allowed the piston rings to scrape the lubricants more often. After the piston ring has passed, the oil film can be maintained for a certain duration without breakage. Therefore, all the experimental groups exhibited a certain oil film thickness in one stroke. The performance of the oil film depended on the thickness of the oil film, i.e., the value of the contact resistance. The ranking of the contact resistances was opposite to the ranking of the friction coefficients above. From small to large, the ranking of the contact resistance was groups A, B, C, and D. This confirms that the interaction between the static and movable oil reservoirs exerted effects at different speeds.

In summary, the oil film characteristics based on the contact resistance coincided with those based on the friction coefficient. Increasing the speed can enhance the oil film distribution in all experimental groups. The texture used can improve the oil film distribution because of its oil storage capacity. The dimple texture on the piston ring served as a mobile oil reservoir, and its lubricant supply capacity was greater than that of the groove texture on the cylinder liner, which served as a static oil reservoir. The complementary features of the co-texture enabled it to possess the optimal film thickness and the best distribution throughout the experiment.

\subsection{Wear topography}

The topographies of the worn surfaces of the piston ring are shown in Fig. 9. By comparing the wear surfaces of the piston rings under operating conditions I and II, it was discovered that the distance between the peak and bottom of the wear surface decreased as the speed increased. This occurred because the increase in speed improved the distribution of the oil film, which reduced both the pressure of wear debris on the piston rings and the wear degree on the surface.

Apparent and regular wear marks were observed, as shown in Figs. 9 A-I and A-II, and the depth and width of the wear marks were the greatest in the four groups of experiments. Running-in removed the sharp areas of the surface and formed wear debris between the cylinder liner and piston ring. Under the applied pressure, the surface was repeatedly damaged. Hence, wear marks were generated. As shown in Figs. 9 C-I and C-II, regular wear marks remained, but the scales of the wear marks were significantly smaller. As a movable debris trap, the dimple texture on the piston ring trapped and stored the debris and reduced its damage to the surface. However, in the reciprocating movement of dimple-textured surfaces, owing to inertia and gravity, the ability to collect debris was reduced. Some debris shifted from the dimple texture and damaged the surface. However, the wear topographies of the piston rings of groups B and D exhibited different characteristics. Although a few wear marks remained on the surface, the flake shedding replaced the regular and uniform wear marks and became the main wear form. As a static debris trap, the groove texture trapped and stored debris while preventing debris from escaping. During the piston ring movement, the debris was swept into the groove texture, and the debris collection ability was enhanced. The flake shedding was primarily caused by the interaction between the lubricant and piston rings at the friction 

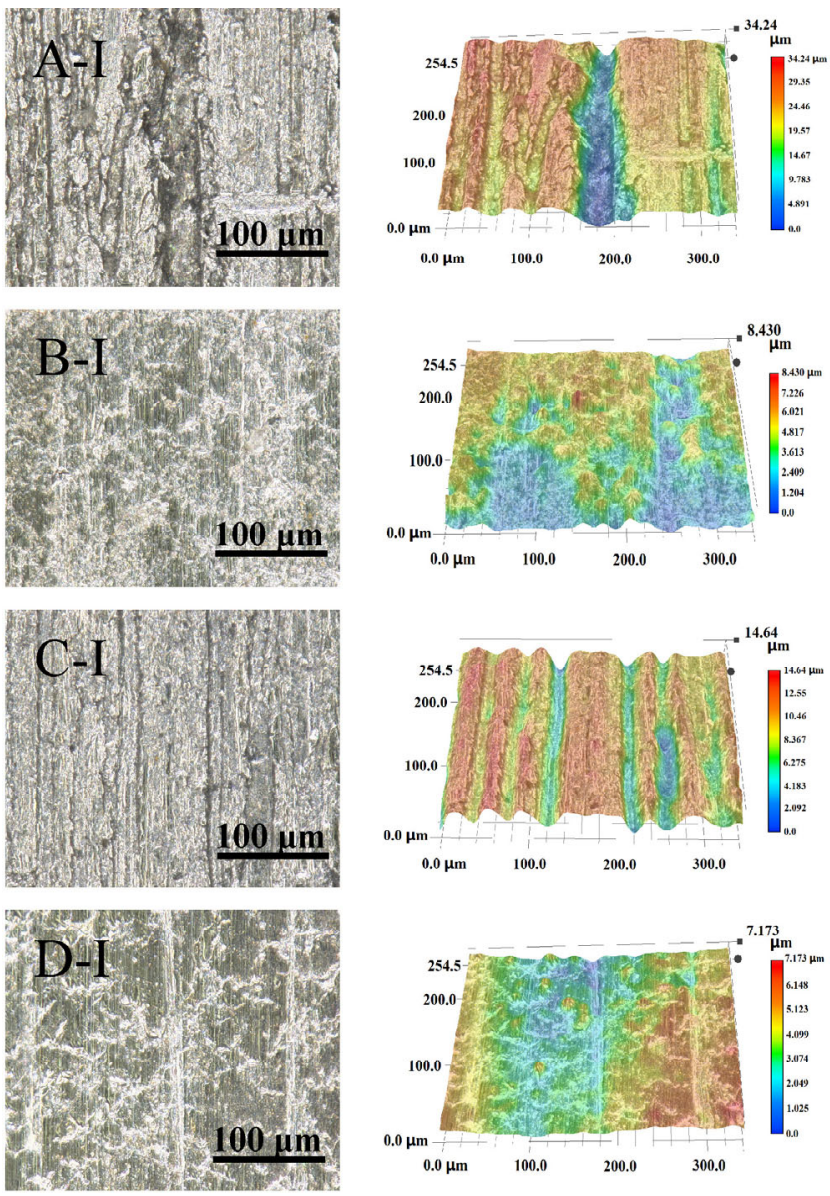
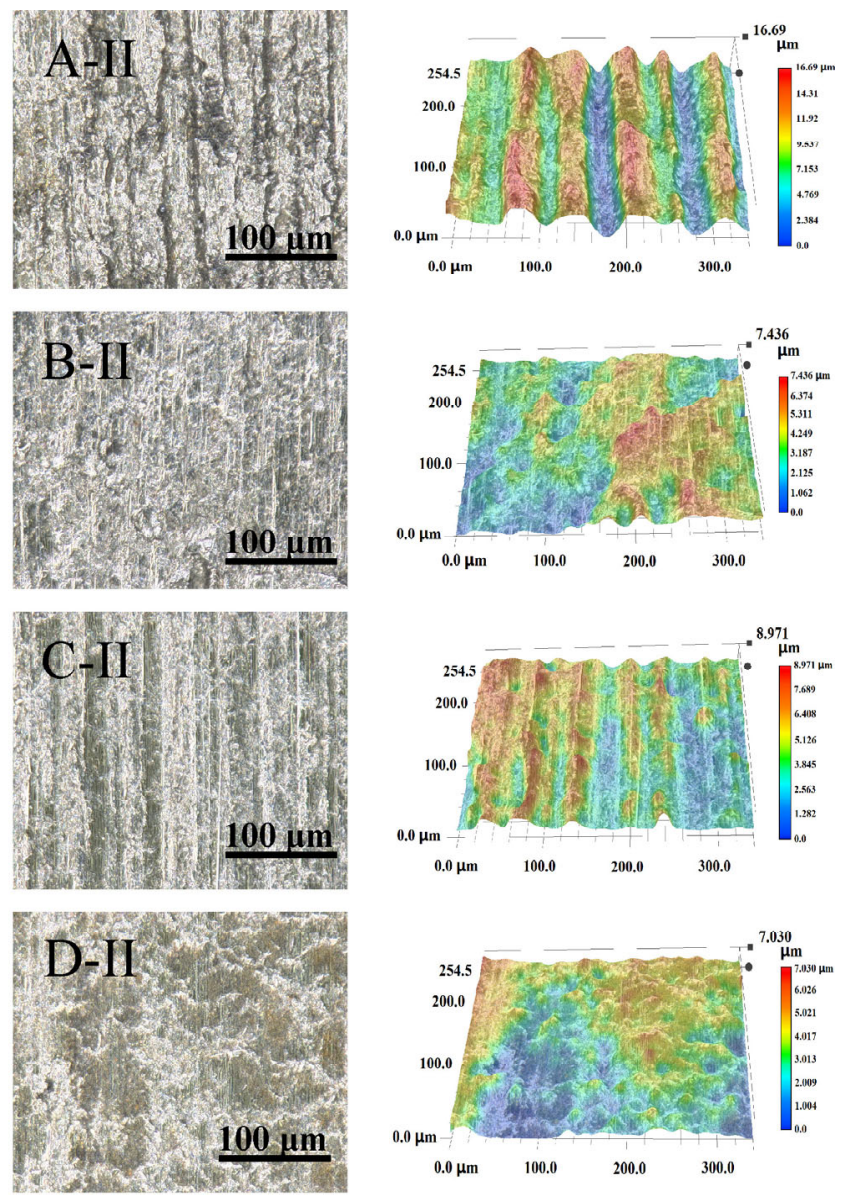

Fig. 9 Worn surface topographies of piston rings (groups A-D, Table 2): I-50 rpm and II-100 rpm.

interface. Because the lubricant had a certain viscosity, it was adsorbed on the piston rings. When the piston rings moved on the oil film, they were subjected to the reaction force of the lubricating oil. To overcome this force, flake shedding was generated on the piston ring surface.

The 3D topography and parameters of the cylinder liners after running-in are listed in Fig. 10. As shown in Fig. 10, the wear marks on the surface of the cylinder liner were uniform. Hence, it can be inferred that the main wear form of the cylinder liner surface was abrasive wear as a result of less oil film movement near the cylinder liner. As the running-in speed increased, $S_{\mathrm{q}}$ and $S_{\mathrm{ci}}$ at the dead center and the middle increased, whereas $S_{\text {bi }}$ decreased. With the increase of speed, the formation of the oil film was easier, even when the surface was rougher, a stable wear process was possible. However, the load-carrying capacity of the cylinder liner surface decreased because of the relatively bumpier surface.
The wear surfaces of the dead center and the middle indicated significant differences. First, the $S_{\mathrm{q}}$ of the dead center was at least $48.0 \%$ larger than that in the middle. This implies that the running-in quality of the middle was much better than that of the dead center. The accumulation of debris and difficulties in oil film establishment caused by low speed resulted in the worsening of wear at the dead center and decreased the running-in quality. Subsequently, the $S_{\text {bi }}$ of the four groups at the dead center was smaller than that in the middle. This indicates that the load-carrying capacity in the middle was stronger. Finally, the $S_{\text {ci }}$ of all groups at the dead centers was smaller than that in the middle. Because of the poor operating conditions of the dead center, the load-carrying capacity and oil storage capacity of the middle were stronger than those at the dead center.

The topographical characteristics of the cylinder liner were consistent with those of the piston rings. The $S_{\mathrm{q}}$ of group A was the largest among those of the 


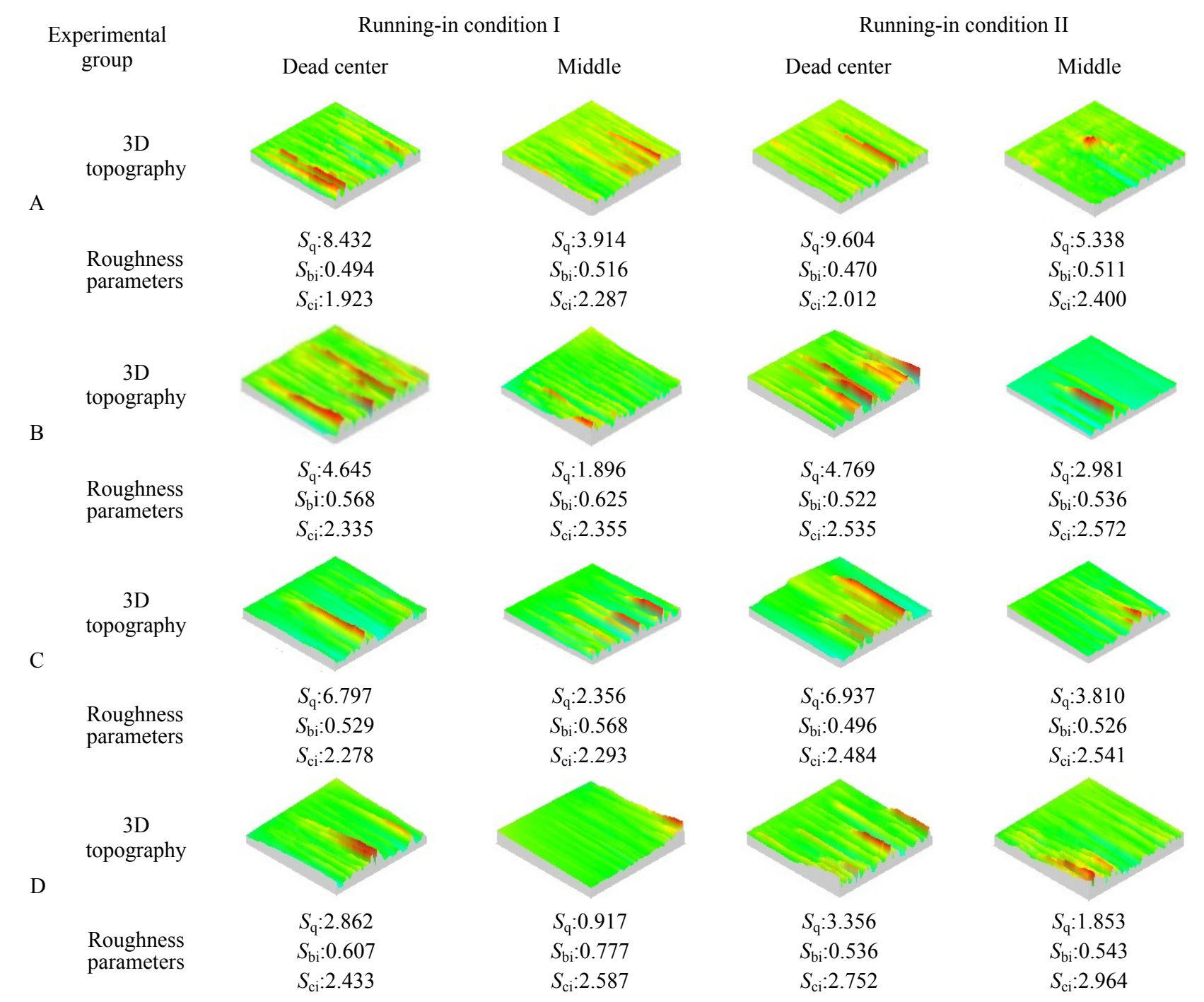

Fig. 10 3D topography and parameters of cylinder liners after running-in (groups A-D, Table 2): I-50 rpm and II-100 rpm.

four groups, followed by those of groups $\mathrm{C}$ and $\mathrm{D}$. The running-in qualities of the cylinder liners from best to worst were ranked as groups D, B, C, and A. The variation in $S_{b i}$ was similar to that of $S_{\mathrm{q}}$, indicating that the loading capacity was in the same order. The oil storage capacity of the running-in surface depended on $S_{\mathrm{ci}}$ and showed the same trend as that of the contact resistance. These topographical parameters show that the co-texture effectively improved the surface smoothness, load-carrying capacity, and oil storage capacity of the contact surface, compared with the non-textured and single-textured surfaces.

\subsection{Coupling mechanism}

Based on the previous analysis, it was discovered that using surface texture as surface treatment reduced friction, improved the oil film, and resisted wear. For the dimple texture on the piston ring as a mobile oil reservoir, its lubricant supply capacity was greater than that of the groove texture on the cylinder liner, which served as a static oil reservoir. By contrast, the running-in quality of the dimple texture as a movable debris trap was weaker than that of the groove texture on the cylinder liner.

The co-texture combines the advantages of the dimple and groove textures to yield an optimal lubrication performance. Figure 11 shows a schematic diagram of the co-texture's coupling mechanism. The dimple texture stored the lubricant. However, with the reciprocating motion of the piston rings, particularly 


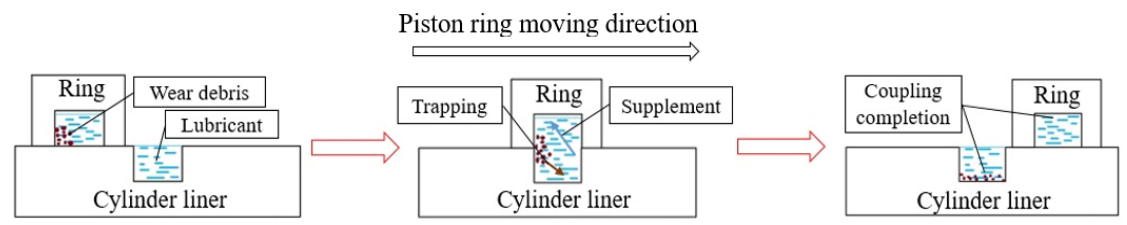

Fig. 11 Schematic diagram of the co-textured coupling mechanism.

during reverse motions at the dead center, lubricating oil loss occurred in the dimple texture. At this time, the groove texture on the cylinder liners served as the filling station. When the piston ring passed through the groove texture, the lubricant was drawn into the groove texture owing to the inlet suction mechanism. When the piston ring left the groove texture, the groove texture was refilled with lubricant. Meanwhile, the dimple texture trapped the debris. When the groove texture was absent, some collected debris escaped and damaged the contact surface owing to the reciprocating motion. When a groove texture was present on the cylinder liners, the groove texture served as collectors. The debris trapped by the dimple texture was washed into the groove texture because of the oil pressure. Owing to the favorable oil film distribution and efficient debris trapping, the running-in quality, load carrying capacity, and oil storage capacity of the co-texture improved.

\section{Conclusions}

A co-texture was formed by processing the texture on both sides of cylinder liners and piston rings based on a single texture. The tribological performance of non-textured surface and textured surfaces, i.e., dimple texture on piston rings, groove texture on cylinder liners, and co-texture on both sides, were investigated. A series of experiments were conducted using a slicing tester at two different running-in speeds. A comparative analysis was performed based on the friction coefficient, contact resistance, and wear topography, and the wear mechanism of the texture was discussed. The following conclusions were obtained:

1) Three types of surface textures can improve the friction performance of CLPRs during running-in under the experimental conditions. Among them, the co-texture yielded the optimum tribological performance, particularly at the dead center. Compared with the non-textured surface, the average friction coefficient of the co-texture reduced by $34.2 \%$ and $44.5 \%$ at 50 and $100 \mathrm{rpm}$, respectively. The average contact resistance of the co-texture increased by $352.9 \%$ and $92.4 \%$ at 50 and $100 \mathrm{rpm}$, respectively.

2) The dimple texture on the piston ring, as a mobile oil reservoir, provided lubrication to the piston rings at all time. Its lubricant supply capacity was greater than that of the groove texture on the cylinder liner, which served as a static oil reservoir. By contrast, the dimple texture on the piston ring served as a movable debris trap, and debris was able to escape. Its wear resistance was weaker than that of the groove texture on the cylinder liner, which served as a static debris trap, but remained stronger than that of a non-textured surface.

3) Compared with non-textured and single-textured surfaces, the co-texture combined the advantages of dimple and groove textures. The coupling effect of the co-texture provided the surface with the optimal oil film thickness and the highest debris trapping efficiency. The co-textured CLPR yielded the best running-in quality.

The feasibility of adopting a co-texture was confirmed, and the tribological performance of the co-texture during running-in was characterized under different experimental conditions. Further studies are being conducted to analyze the tribological performance of co-textured CLPRs using a theoretical model.

\section{Acknowledgements}

The authors would like to express their sincere gratitudes to the National Natural Science Foundation of China (51422507), Hubei Provincial Natural Science Foundation of China (2018CFB483), and Excellent Dissertation Cultivation Funds of Wuhan University of Technology (2018-YS-041).

Open Access This article is licensed under a Creative Commons Attribution 4.0 International License, which 
permits use, sharing, adaptation, distribution and reproduction in any medium or format, as long as you give appropriate credit to the original author(s) and the source, provide a link to the Creative Commons licence, and indicate if changes were made.

The images or other third party material in this article are included in the article's Creative Commons licence, unless indicated otherwise in a credit line to the material. If material is not included in the article's Creative Commons licence and your intended use is not permitted by statutory regulation or exceeds the permitted use, you will need to obtain permission directly from the copyright holder.

To view a copy of this licence, visit http://creativecommons.org/licenses/by/4.0/.

\section{References}

[1] Chi H T, Jiang L T, Chen G Q, Qiao J, Lin X, Wu G H. The tribological behavior evolution of $\mathrm{TiB}_{2} / \mathrm{Al}$ composites from running-in stage to steady stage. Wear 368-369: 304-313 (2016)

[2] Archard J F. Contact and rubbing of flat surfaces. J Appl Phys 24(8): 981-988 (1953)

[3] Zhang Y Z, Kovalev A, Meng Y G. Combined effect of boundary layer formation and surface smoothing on friction and wear rate of lubricated point contacts during normal running-in processes. Friction 6(3): 274-288 (2018)

[4] Wang W, Wong P L, Guo F. Application of partial elastohydrodynamic lubrication analysis in dynamic wear study for running-in. Wear 257(7-8): 823-832 (2004)

[5] Federici M, Perricone G, Gialanella S, Straffelini G. Sliding behaviour of friction material against cermet coatings: pin-on-disc study of the running-in stage. Tribol Lett $\mathbf{6 6}(2)$ : 53 (2018)

[6] Rao X, Sheng C X, Guo Z W, Yuan C Q. Effects of thread groove width in cylinder liner surface on performances of diesel engine. Wear 426-427: 1296-1303 (2019)

[7] Lengiewicz J, Stupkiewicz S. Efficient model of evolution of wear in quasi-steady-state sliding contacts. Wear 303(1-2): 611-621 (2013)

[8] Yousfi M, Mezghani S, Demirci I, El Mansori M. Smoothness and plateauness contributions to the running-in friction and wear of stratified helical slide and plateau honed cylinder liners. Wear 332-333: 1238-1247 (2015)

[9] Zhang Y, Chen G D, Wang L. Thermoelastohydrodynamic analysis of misaligned bearings with texture on journal surface under high-speed and heavy-load conditions. Chin J Aeronaut 32(5): 1331-1342 (2019)
[10] Arslan A, Masjuki H H, Varman M, Kalam M A, Quazi M M, Al Mahmud K A H, Gulzar M, Habibullah M. Effects of texture diameter and depth on the tribological performance of DLC coating under lubricated sliding condition. Appl Surf Sci 356: 1135-1149 (2015)

[11] Obert P, Müller T, Füßer H J, Bartel D. The influence of oil supply and cylinder liner temperature on friction, wear and scuffing behavior of piston ring cylinder liner contacts - A new model test. Tribol Int 94: 306-314 (2016)

[12] Wos S, Koszela W, Pawlus P, Drabik J, Rogos E. Effects of surface texturing and kind of lubricant on the coefficient of friction at ambient and elevated temperatures. Tribol Int 117: 174-179 (2018)

[13] Yu A B, Niu W Y, Hong X, He Y, Wu M C, Chen Q J, Ding M L. Influence of tribo-magnetization on wear debris trapping processes of textured dimples. Tribol Int 121: 84-93 (2018)

[14] Guo Z W, Yuan C Q, Liu P, Peng Z X, Yan X P. Study on influence of cylinder liner surface texture on lubrication performance for cylinder liner-piston ring components. Tribol Lett 51(1): 9-23 (2013)

[15] Vlădescu S C, Ciniero A, Tufail K, Gangopadhyay A, Reddyhoff T. Looking into a laser textured piston ring-liner contact. Tribol Int 115: 140-153 (2017)

[16] Gu C X, Meng X H, Zhang D. Analysis of the coated and textured ring/liner conjunction based on a thermal mixed lubrication model. Friction 6(4): 420-431 (2018)

[17] Profito F J, Vlădescu S C, Reddyhoff T, Dini D. Transient experimental and modelling studies of laser-textured microgrooved surfaces with a focus on piston-ring cylinder liner contacts. Tribol Int 113: 125-136 (2017)

[18] Morris N, Rahmani R, Rahnejat H, King P D, Howell-Smith S. A numerical model to study the role of surface textures at top dead center reversal in the piston ring to cylinder liner contact. J Tribol 138(2): 021703 (2016)

[19] Yin B F, Sun S, Wang B W, Qian Y Q. Numerical research on tribological performance of textured liner surface under different combustion modes. J Eng Gas Turbines Power 139(1): 011504 (2017)

[20] Guo Z W, Yuan C Q, Bai X Q, Yan X P. Experimental study on wear performance and oil film characteristics of surface textured cylinder liner in marine diesel engine. Chin J Mech Eng 31(1): 52 (2018)

[21] Shen Y, Lv Y, Li B, Huang R, Yu B, Wang W, Li C, Xu J. Reciprocating electrolyte jet with prefabricated-mask machining micro-dimple arrays on cast iron cylinder liner. $J$ Mater Process Technol 266: 329-338 (2019)

[22] Mohamad S A, Lu X, Zheng Q. Numerical modeling of lubrication of piston ring of two-stroke marine diesel engine considering the effect of multi-scale grooves on the cylinder liner. Proc Inst Mech Eng Part J 229(8): 989-1002 (2015) 
[23] Rao X, Sheng C X, Guo Z W, Yuan C Q. Influence of surface groove width on tribological performance for cylinder linerpiston ring components. Tribol Trans 62(2): 239-248 (2019)

[24] Wan Y, Li J, Xiong D. Tribological property of texturedcoating on piston ring surface. Surf Technol 47(6): 195-201 (2018) (in Chinese)

[25] Kligerman Y, Etsion I, Shinkarenko A. Improving tribological performance of piston rings by partial ribological and sealing performance of laser pocketed piston rings in a diesel enginesurface texturing. J Tribol 127(3): 632-638 (2005)

[26] Shen C, Khonsari M M. Tribological and sealing performance of laser pocketed piston rings in a diesel engine. Tribol Lett 64(2): 1-9 (2016)

[27] Zhang Y L, Zhang X G, Wu T H, Xie Y B. Effects of surface texturing on the tribological behavior of piston rings under lubricated conditions. Ind Lubr Tribol 68(2): 158-169 (2016)

[28] Ezhilmaran V, Vasa N J, Vijayaraghavan L. Investigation

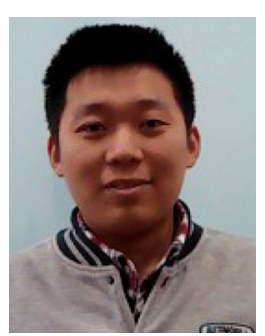

Chenwei MIAO. He received his B.S. degree in marine engineering in 2015 from Wuhan University of Technology, Wuhan, China. He received his M.S. degree in marine

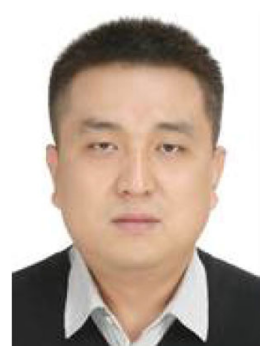

Zhiwei GUO. He received his B.S. degree in mechanical engineering and automation in 2008 from Wuhan University of Technology, Wuhan, China. He received his M.S. and Ph.D. degrees in vehicle utilization engineering from Wuhan University

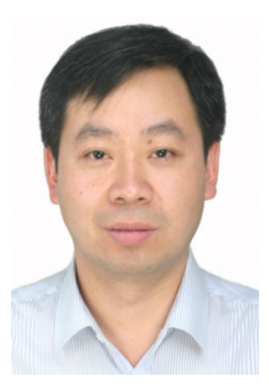

Chengqing YUAN. He received his B.S. degree in chemical engineering in 1998 from Wuhan University of Automobile Technology, Wuhan, China. He received his M.S. degree in mechanical design and theory from Wuhan Material Protection Research Institute, Wuhan, China, in on generation of laser assisted dimples on piston ring surface and influence of dimple parameters on friction. Surf Coat Technol 335: 314-326 (2018)

[29] Miao C W, Guo Z W, Yuan C Q. An experimental study on tribological properties and air tightness of co-textured cylinder liner-piston ring on an engine tester. Surf Topogr: Metrol Prop 9: 015005 (2021)

[30] Deltombe R, Kubiak K J, Bigerelle M. How to select the most relevant 3D roughness parameters of a surface. Scanning 36(1): 150-160 (2014)

[31] Clarke A, Weeks I J J, Evans H P, Snidle R W. An investigation into mixed lubrication conditions using electrical contact resistance techniques. Tribol Int 93: 709-716 (2016)

[32] Olver A V, Fowell M T, Spikes H A, Pegg I G. 'Inlet suction', a load support mechanism in non-convergent, pocketed, hydrodynamic bearings. Proc Inst Mech Eng Part J: J Eng Tribol 220(2): 105-108 (2006)

engineering in 2020 from Wuhan University of Technology, Wuhan, China. His research interests include surface texturing and tribology of internal combustion engine.

of Technology, Wuhan, China, in 2010 and 2014, respectively. His current position is an associate professor and a Ph.D. supervisor at the School of Energy and Power Engineering, Wuhan University of Technology. His research areas cover tribology and surface interface technology of marine power machinery.

2001. He received his Ph.D. degree in vehicle utilization engineering from Wuhan University of Technology, Wuhan, China, in 2005. His current position is a professor and a Ph.D. supervisor at the School of Energy and Power Engineering, Wuhan University of Technology. His research areas cover marine power system reliability and green technology. 